\title{
OS PARADOXOS DO DESENVOLVIMENTO AMAZÔNICO E AS ALTERAÇÕES HIDROAMBIENTAIS
}

Mónica Montana M. ${ }^{1}$

\section{Resumo}

No princípio 11 da Conferência de Rio-92 foi destacado que as políticas ambientais de todos os Estados devem fortalecer e não afetar de maneira adversa o potencial de desenvolvimento presente e futuro dos países. Uma questão sensível no marco das preocupações internacionais e das discussões locais, regionais e globais envolve temas como o desenvolvimento e a preservação ambiental na Amazônia Continental e a gestão integrada da Bacia Amazônica. Este artigo, resultado de pesquisa doutoral sobre hidropolítica amazônica, aborda alguns dos empreendimentos que pretendem o desenvolvimento regional sulamericano e explana acerca das alterações hidro-ambientais no contexto amazônico proveniente de tais iniciativas.

Palavras Chaves: Desmatamento, Bacia Hidrológica Amazônica, Alterações Hidroambientais, Desenvolvimento Regional; IIRSA; UNASUL.

\section{INTRODUÇÃO}

Pelas condições de isolamento físico das áreas amazônicas faz-se necessária, para atrair o seu desenvolvimento humano e econômico, realizar obras de infraestrutura. Contudo, sabe-se que com a intervenção da ação antropogênica sobre os espaços amazônicos e o avanço de projetos de crescimento econômico, sem planejamentos acordes com as características físicas e sociais, em cada país, que integra a Amazônia Continental, poder-se-á esperar vários tipos de impactos hidroambientais, sociais e culturais (MONTANA, 2012).

Salvo localizadas exceções, persiste nos países amazônicos uma visão periférica sobre suas áreas amazônicas. O resultado disso tem sido erros nas políticas públicas, baixo investimento na saúde, na educação, na preservação hidroambiental, além de resultados pouco eficazes na promoção de um desenvolvimento realmente sustentável (PROCÓPIO, 1997; ESQUIVEL, 1998; PROCÓPIO, 2007; MONTANA, 2012).

A acelerada transformação do território amazônico e o impacto sobre seus ecossistemas têm provocado preocupações entre a população local e entre diversos movimentos sociais e ONGs, razões não faltam, a Amazônia Continental apresenta-se com notável destaque ecológico, hídrico e ambiental no cenário internacional, ao tratarse de uma região de características únicas que reúne grandes sistemas naturais interconectados (água, solo, vegetação, clima), que possibilitam abundante riqueza

\footnotetext{
${ }^{1}$ Doutoranda em Relações Internacionais e Desenvolvimento Regional, Universidade de Brasília.
} 
biológica, mineral, florestal e hídrica. Adicionalmente, é um espaço de rica diversidade étnica, cultural e linguística. Sem esquecer, que se trata do lugar de maior biodiversidade do planeta (MONTANA, 2012). Apesar de toda essa riqueza em recursos naturais, humanos e culturais, é quase homogênea a pobreza e os baixos níveis de desenvolvimento de seus habitantes. São regiões que se comparadas com o restante de seus países, carecem de eficientes serviços básicos, transporte, telecomunicações, segurança, possibilidades empregatícias e alfabetização (ARAGÓN, 2005; PROCÓPIO, 2007; PNUMA, OTCA e UNIVERSIDADE DO PACÍFICO, 2008).

Esse cenário, evidência um dos paradoxos mais antigos: como desenvolver a Amazônia sem destruí-la?

\section{INICIATIVAS DE INTEGRAÇÃO FÍSICA E POLÍTICA NO MARCO DA IIRSA E DA UNASUL}

No ano 2000, teve origem a Iniciativa para a Integração da Infraestrutura Regional Sul-Americana IIRSA ${ }^{2}$, cuja implementação foi prevista para um período de 10 anos. Esse empreendimento dos doze países sul-americanos, focado no desenvolvimento da infraestrutura de transporte, energia e telecomunicações, através da integração física da região, é uma concretização dos esforços políticos e econômicos de maior representação no contexto da cooperação e a integração regional.

A idéia de formar a IIRSA se originou a partir da experiência brasileira de planejamento territorial, conhecida como Estudo dos Eixos, realizada pelo Ministério do Planejamento (MP) em conjunto com o Banco Nacional de Desenvolvimento Econômico e Social (BNDES) no ano 2000, que planejava o país a partir de regiões identificadas por seu inter-relacionamento econômico (BRASIL, 2012). Assim, a IIRSA surgiu efetivamente, naquele ano, no mês de agosto, a partir da reunião dos doze Chefes de Estado da América do Sul, ocorrida em Brasília.

Expirado o tempo da IIRSA, seus projetos foram assumidos pela União de Nações Sul-Americanas UNASUL, por meio do Conselho de Infraestrutura e Planejamento COSIPLAN. A UNASUL, como se sabe, é um organismo de âmbito regional, conformado pelos doze países sul-americanos, criada com base nos avanços da

\footnotetext{
${ }^{2}$ O plano foi criado oficialmente durante a Reunião dos Presidentes da América do Sul, em Brasília. A coordenação operacional da IIRSA está a cargo da Corporación Andina de Fomento (CAF), do Banco Interamericano de Desenvolvimento (BID) e do Fundo Financeiro para o Desenvolvimento da Bacia do Prata (Fonplata). As negociações para a concretização da IIRSA evoluíram no período presidencial de Luiz Inácio Lula da Silva.
} 
III SEMINÁRII ECDLOGIA

POLÍTICA

E DIREITO NA AMÉRICA LATINA

Comunidade Sul-Americana de Nações (CASA), por ocasião da I Cúpula Energética da América do Sul, na Isla Margarita, em abril de 2007 (MONTANA, 2012).

Esse organismo foi formalmente constituído em Brasília, em 23 de maio de 2008, o Tratado representa um abrangente compromisso político que pretende "construir una identidad y ciudadanía suramericanas y desarrollar un espacio regional integrado en lo político, económico, social, cultural, ambiental, energético y de infraestructura, para contribuir al fortalecimiento de la unidad de América Latina y el Caribe" 3 . Nessa ocasião, aprovou-se a realização de ações conjuntas para impulsionar o processo de integração política, econômica e social da América do Sul, incluindo a modernização da infraestrutura regional e ações específicas para estimular a integração e o desenvolvimento de sub-regiões isoladas.

Pode-se dizer que a integração da infraestrutura física regional e os projetos energéticos constituem prioridades da política externa brasileira, conformando temas importantes na agenda multilateral dos países da América do Sul (MONTANA, 2012). Isso é perceptível porque em 10 anos de existência a IIRSA desenvolveu importante trabalho, com uma carteira de 520 projetos, ordenada ao longo de 10 Eixos de Integração e Desenvolvimento ${ }^{4}$, tal como ilustrados na figura 1 , a seguir.

Cabe destacar que as faixas geográficas dos 12 países sul-americanos são aquelas áreas que concentram ou que possuem potencial para desenvolver bons fluxos comerciais, visando formar cadeias produtivas e assim estimular, o desenvolvimento regional. Note-se que boa parte dos projetos estão concentrados na Amazônia Andina. Essa concentração de projetos nas áreas amazônicas permite deduzir que os antigos planos destinados à produção energética da Amazônia e seu aproveitamento navegável continuam sendo interesses centrais dos atores estatais ${ }^{5}$. O eixo Peru-Brasil-Bolívia merece destaque em termos hidropolíticos, pois as obras de infraestrutura navegacional e de cooperação energética, em curso, são de alta envergadura e importância para o

\footnotetext{
${ }^{3}$ Tratado Constitutivo da Unasul http://www.comunidadandina.org/unasur/tratado_constitutivo.htm.

${ }^{4} \mathrm{http} / / / \mathrm{www}$. itamaraty.gov.br/sala-de-imprensa/notas-a-imprensa/conselho-de-infraestrutura-eplanejamento-cosiplan-da-unasul-rio-de-janeiro-28-de-abril-de-2011.

${ }^{5}$ Em setembro de 2005 foi promovida a I Reunião de Chefes de Estados da Comunidade Sul Americana de Nações; ocasião em que os doze presidentes se comprometeram a buscar fontes de financiamento que levassem em conta a realidade financeira dos países sul- americanos, preservassem a capacidade e autonomia decisória dos Estados e estimulassem a realização de investimentos necessários para a implementação dos projetos prioritários realizados na Carteira IIRSA. Além disso, reafirmaram a importância da integração energética da América do Sul, e ratificaram os resultados da I Reunião de Ministros de Energia da Comunidade Sul-Americana de Nações (MONTANA, 2012).
} 


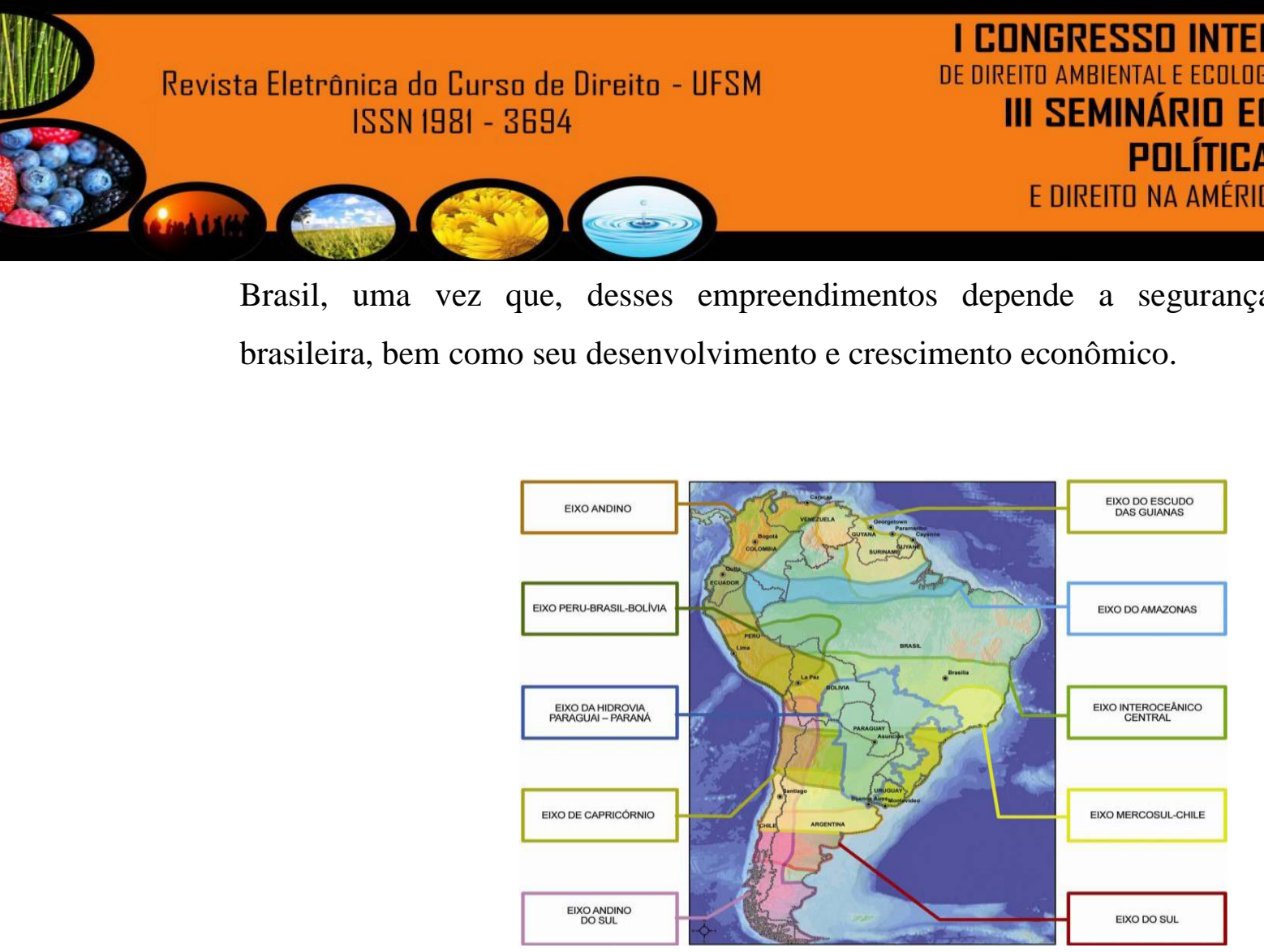

Figura 1. Planejamento territorial indicativo Eixos Carteira de Projetos IIRSA Fonte: IIRSA. Carteira de Projetos da IIRSA (2009:14)

Nesse âmbito merece ser lembrado que os interesses brasileiros concentram-se nos empreendimentos energéticos realizados no âmbito dos Programas de Aceleramento PAC 1. Projetos que ainda vão se concretizar no PAC2 até 2014, como ilustra a figura 2 a seguir.

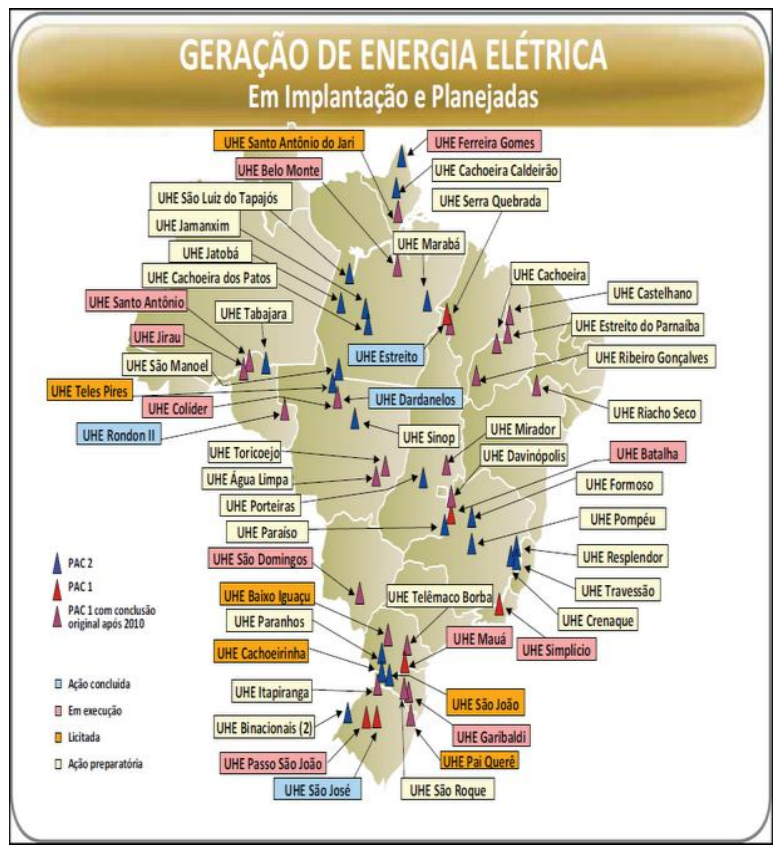




sistemas e subsistemas naturais (cobertura vegetal, por exemplo). Devido a sua interconexão, uma alteração em algum deles implica na necessária alteração do outro.

Essas afirmações têm sustento em estudos científicos de diferentes áreas, sendo comprovadas em estudos hidrológicos específicos. O Programa Hidrológico Internacional (PHI, 2002:24), por exemplo, menciona que "os ciclos hidrológicos regionais estão fortemente ligados com as condições climáticas existentes e com as coberturas vegetais associadas", pelo que cabe esperar que reajam de acordo às modificações "do forçamento meteorológico ou às transformações em grande escala da cobertura superficial" ou do solo. Os estudos de Peter H. Gleick ${ }^{6}$ reforçam também essas interconexões e seus efeitos. Em diversos trabalhos de pesquisadores e agências da ONU são ressaltadas essas relações de interdependência, e se alerta sobre a influência das ações antrópicas. Por exemplo, para Gleick (1998:140), “The hydrologic system - an integrated component of the earth's geophysical system - both affects and is affected by climatic conditions". O conjunto dessas relações e o seu desequilíbrio foram apontados também por Marcus Moench (2005), num trabalho que integra o reporte bienal de água doce 2004-2005, publicado por Peter H. Gleick, sobre águas subterrâneas.

Os fatores antropogênicos foram apontados, em vários estudos, como a origem principal das alterações que lesam o equilíbrio entre esses sistemas interconectados, afetando notoriamente o ciclo hidrológico global, causando modificações no sistema climático também. Adicionalmente, por tratar-se de sistemas interconectados, as alterações nos sistemas hídricos alteram por sua vez a qualidade do solo. Merece ser destacado que se tratando de um complexo sistema de interdependência hídrica, a umidade e a qualidade do solo se vêm afetadas pelo desmatamento, o qual ocasiona redução da evapotranspiração (PHI, 2002; NEPSTAD, 2006; NEPSTAD, 2007; PNUMA, OTCA e Universidade do Pacífico 2008; IPAAM, 2009).

\footnotetext{
${ }^{6}$ Peter H. Gleick reuniu em quatro volumes, trabalhos de pesquisa de diferentes áreas que demonstram a delicada interconexão das águas e seus impactos multidimensionais. O primeiro dos reportes bienais sobre as águas doces foi o de 1998-1999. The World's Water 1998-1999: The Biennale Report on Freshwater Resources (1998) Washington, Island Press. O ultimo relatório foi o de 2004-2005. O primeiro trabalho de Gleick deu origem a uma retórica de escassez hídrica que foi sancionada no Segundo Fórum Mundial da Água realizado em Haia em março de 2000, no qual se destaca a crescente preocupação mundial sobre suprimentos de água potável e a complexidade das questões que devem ser enfrentadas por países em desenvolvimento para atender demandas futuras de água (Cosgrove e Rijsberman 2000).
} 
Em tal direção, o Programa Hidrológico Internacional (2002) também destacou que as maiores causas desse desequilíbrio têm origem na irrigação, na agricultura, na drenagem de zonas úmidas, na desflorestação, na transformação do território, na urbanização e no incremento da emissão de gases de efeito estufa ${ }^{7}$, dentre outras causas. Junto a isso, ratificou que a destruição das florestas nas bacias hidrológicas do mundo inteiro representa uma das ingerências mais sérias da intervenção antrópica nos ecossistemas, porque o desmatamento e a derrubada de florestas atingem seriamente as águas, alterando o equilíbrio hídrico, responsável por manter regulada a umidade atmosférica, o clima e os regimes de chuva. Além disso, possui efeitos erosivos no solo.

O PHI (2002:24) destacou que em áreas de florestas tropicais desmatadas a diminuição das precipitações é notável, em função da redução da evapotranspiração. Alertou, também, que esses processos por sua vez incidem no aumento de áreas desérticas e na baixa umidade do ar, cujos efeitos são variados e têm incidência na alteração dos regimes de chuvas e no clima de forma local $^{8}$, regional e global. Em função disso, os estudos do PHI mostraram alterações significativas nos regimes de chuvas nos espaços amazônicos.

No caso da floresta amazônica, os estudos do PHI (2002:28) indicaram a redução em 30\% do regime de chuvas em nível regional. Com base nessa informação e em pesquisas recentes que evidenciam o incremento da derrubada de florestas, o aumento da agropecuária e a danificação do solo, devem considerar-se os impactos locais e regionais derivados dessas questões; toda vez que afeta a produção hídrica, altera o clima e afeta o solo com a erosão de algumas áreas.

Adicionalmente, o PHI (2002:28) informa que a redução das florestas diminui a produção de água, tal como se depreende da seguinte citação:

La deforestación de los bosques tropicales produce tremendas reducciones de la evapotranspiración, y en consecuencia, de la lluvia. Mientras que las

\footnotetext{
${ }^{7}$ De forma sucinta o PHI (2002) explica: el calentamiento global del es resultado del efecto invernadero, que, básicamente, ocurre porque "la tierra está cubierta por una capa de gases que atrapa alguna radicación solar que se reflejan en la superficie de la tierra y que normalmente debería dirigirse hacia el espacio. Estos gases denominados gases invernadero son el vapor de agua, el dióxido de carbono, los clorofluorocarbonos, el metano, el óxido de nitrógeno, entre otros gases.

${ }^{8}$ Embora sendo um caso local, cabe mencionar que no mês de junho de 2011, o estado de Roraima registrou uma das mais severas alterações no seu regime de chuvas, o que provocou, consequentemente, grandes inundações. No dia 7 de agosto de 2011, o Jornal da Globo informou, com base em registros meteorológicos brasileiros, que "o nível de umidade na Amazônia brasileira chegou a um nível nunca experimentado porque era um valor característicos dos climas de desertos".
} 
simulaciones iniciales de la conversión a gran escala del bosque pluvial amazónico en pastizales predicen importantes reducciones en las precipitaciones regionales (hasta un 30\%), las recientes simulaciones que se basan en modelos refinados muestran un efecto más limitado. En particular, la eliminación de los bosques tropicales ocasiona condiciones desastrosas. A menudo, a los flujos de agua en manto y a las inundaciones de la época húmeda sigue una falta de agua durante la época de sequía. Esto se debe a una pérdida de la capacidad de almacenamiento de los terrenos a causa de la erosión (grifos meus).

Por suas funções tanto no ciclo hidrológico, quanto no ciclo global de carbono, a importância da Amazônia Continental é notória. Cabe, em função disso, salientar a relevância que a prevenção desses impactos adquire nas áreas amazônicas dos oito países membros da OTCA e no Departamento Ultramarino da França (Guiana Francesa), e como tal situação realça o papel da Hidropolítica e a importância da elaboração de regimes comuns a todas as áreas amazônicas. Isso é enfaticamente importante, considerando que os efeitos nocivos sob as águas não respeita fronteiras nacionais e, atinge à floresta de forma correlacionada. Frente a isso, resulta de marcada importância o traçado de políticas públicas que sejam condizentes com as características únicas desses espaços, para estimular um desenvolvimento racional e sustentável. Nisso radica, por outro lado, a importância do adequado gerenciamento hídrico, territorial e de desenvolvimento.

Assim sendo, torna-se fundamental prever que, certamente, os países que integram essas áreas amazônicas irão se desenvolver e com isso, em alguns casos, propiciar o aumento dos índices de gases na atmosfera, bem como a poluição das águas, além de ocasionar maiores pressões nos sistemas hídricos devido à transformação do solo.

Considerar esses aspectos de forma integrada é fundamental, uma vez que os solos das regiões situadas entre $40^{\circ}$ Norte e $40^{\circ}$ Sul do Equador, tal como salientado pelo PHI (2002), são altamente susceptíveis à deterioração ambiental quando a cobertura vegetal é retirada. Uma das razões para tais afirmações tem sustento no tipo das chuvas que caem nessas áreas. Isso porque, quando chove, o impacto das gotas de chuva sobre o solo pode desencadear erosão ${ }^{9}$ e causar assoreamento, enquanto que as fortes precipitações arrastam e retiram os nutrientes do solo, empobrecendo-o. Porém, como

\footnotetext{
${ }^{9} \mathrm{O}$ dano causado pelo impacto de uma gota de chuva no solo por uma chuva tropical é muitas vezes maior do que o dano causado por chuvas de regiões de climas temperados, que, segundo estimativas, é 260 vezes maior do que a energia de enxurrada (HUDSON, 1997).
} 
adverte Righes (2000:93), “o problema não reside somente na quantidade de chuva que cai, mas também no tipo de chuva e a energia cinética".

Dessa forma, na busca de um adequado gerenciamento para a Bacia Amazônica, não pode deixar de se investir em programas e pesquisas científicas formatadas e desenvolvidas com o propósito de desvendar, elucidar e tornar compreensiva a dinâmica de funcionamento dos sistemas hidrológicos amazônicos, suas estruturas e suas dinâmicas para aproveitar, sem dilapidar, os recursos que a floresta oferece.

O desmatamento em grande escala, como se sabe, tem sido um impacto severo nos espaços amazônicos, esse impacto interfere também nos mecanismos hídricos. Tem efeitos sérios ao causar erosão do solo, diminuindo a produção de água ao reduzir a evapotranspiração. Além desses efeitos, produz incremento de temperatura nas áreas devastadas ${ }^{10}$. Assim sendo, haverá de se considerar que o desmatamento e a drenagem a grande escala procedente das zonas úmidas tem como consequência no sistema hídrico a restrição da evapotranspiração. Fenômeno que afeta a quantidade de água necessária no balanço hídrico que evapora naturalmente sobre áreas conexas, e que, somada à exsudação das plantas, posteriormente retorna à superfície da Terra, em forma de chuvas. De tal forma, é de esperar-se que ao haver uma modificação das coberturas vegetais na Amazônia haja também uma modificação no clima de forma local e regional. De fato, as alterações do clima e dos regimes de chuva estão documentados em diversas pesquisas, sendo vinculados às transformações severas do solo.

Assim, as características de cada área amazônica, pelo que se expôs, deverão induzir a planejamentos coerentes de ocupação do território e de planos de desenvolvimento da região específicos; ou seja, a partir disso, se impõe um gerenciamento adequado às bacias hidrológicas. Como se aprecia, gerenciar um sistema natural tão complexo como o amazônico, requer necessariamente conhecer e compreender suas dinâmicas.

O PHI (2002:27) explica que “a perda do conteúdo de água atmosférico, que está associado a uma escassa evaporação tem como repercussão a diminuição das precipitações". Entretanto, destaca que a diminuição nas precipitações, em um local determinado ou em vários ao mesmo tempo, depende em grande parte das reações que

\footnotetext{
${ }^{10}$ Seus efeitos se podem notar facilmente porque as árvores normalmente utilizam mais água que as terras de pasto ou os cultivos agrícolas, nesse sentido é possível sentir a falta de umidade, produzindo mudanças no clima local e regional.
} 
se sucedem na atmosfera, sendo que os gases presentes nela inibem ou estimulam os períodos de seca ou de intensa chuva.

Assim, pela interligação existente entre os sistemas naturais da Amazônia torna-se inquietante o processo acelerado de desmatamento que está ocorrendo por conta da construção de novas barragens e estradas em toda a região. A incerteza sobre os verdadeiros efeitos hidroambientais e sociais, em curto, médio e longo prazo, são latentes, em termos hidrológicos, mas não há indícios de que os grandes projetos hidrelétricos na Amazônia serão cancelados. Entretanto, merece destacar-se que essa questão está sendo levantada de forma enfática pelos movimentos sociais.

A desordenada ocupação do território e a tradicional falta de infraestrutura para o tratamento adequado de água e saneamento básico são questões relevantes a serem consideradas no contexto amazônico. Não apenas pelas vulnerabilidades ambientais e hídricas, mas pelas situações a que a população amazônica será exposta, com o incremento de novas atividades econômicas, que certamente irão acontecer para o desenvolvimento da Amazônia, seja dentro dos projetos bilaterais ou multilaterais no âmbito da IIRSA, do PAC, ou de outros empreendimentos que se projetem futuramente. Em tal contexto, merecem destaque os impactos no bem-estar humano, além dos já referidos impactos hidroambientais.

Para o PNUMA, a OTCA e a Universidade do Pacífico (2008:202), o bem-estar humano refere-se "à capacidade das pessoas de viver o tipo de vida que mais valorizam e à oportunidade de realizar seus desejos". Sabe-se, no entanto, que entre os componentes essenciais ao bem-estar humano estão a saúde, a educação, o emprego, o acesso a infraestrura, entre outras questões importantes. Assim, desde uma visão otimista, é de se esperar que com os projetos em andamento para o desenvolvimento e integração física, como os implementados pelo IIRSA e o PAC, seja possível às populações amazônicas o acesso a transporte, energia e água de qualidade, a preços socialmente justos, assim como melhores e maiores meios de educação, transporte e segurança. 



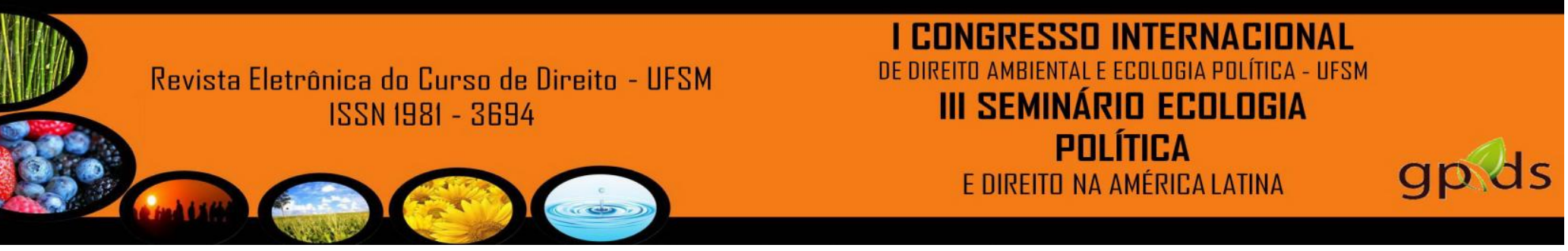

em diferentes graus e entre diferentes atores. Embora se saiba que cabe essencialmente ao Estado procurar o crescimento econômico das regiões menos dinâmicas, em geral por meio de fomento às atividades econômicas motrizes.

Assim, entende-se que o grande desafio dos projetos que pretendam o desenvolvimento amazônico consiste em não perder-se de seu objetivo, qual deve ser: oferecer garantias de que os benefícios do desenvolvimento alcancem, de forma plena, às populações indígenas, às comunidades ripárias e à população em geral. Deverá garantir, com planos de ação contundentes, a minimização de ações deletérias derivadas dos processos de crescimento econômico. E, por fim, deverá estimular e permitir a participação pública.

\section{REFERÊNCIAS}

ARAGÓN, L. População e Meio Ambiente na Pan-Amazônia (Organizador) NAEA. Belém, 2007.

ARGUËLLES. M. Problemas Hidrológicos desencadenados por la polución. Progensa. Sevilla. 1994.

BARRETO, P.; SOUZA Jr. C.; NOGUERÓN, R. ANDERSON, A.; SALOMÃO R. Pressão Humana na Floresta Amazônica. Imazon. Belém: WRI. 2005.

BRAGA, B.; VARELLA, P.; GONÇALVES, H. Transboundary Water Management of The Amazon Basin. In: International Journal of Water Resources Development. Routledge. London. 2011.

BENITES, M.; MAGANHINI, T.; A participação popular como instrumento de proteção da Amazônia na criação das usinas hidrelétricas de Santo Antônio e Jirau. Âmbito Jurídico, 2011. Disponível em: <http://www.ambitojuridico.com.br/site/index.php?n_link=revista_artigos_leitura\&artigo_id=10847. Acesso em: mar 2011.

BRASIL. Ministério de Meio Ambiente. Plano Amazônia Sustentável: Diretrizes para o Desenvolvimento Sustentável da Amazônia Brasileira. Presidência da República. MMA. Brasília. 2008.

BRASIL. Iniciativa para a Integração da Infraestrutura Regional Sul-Americana (IIRSA). Ministério do Planejamento. 2012. Disponível em: $<$ http://www.planejamento.gov.br/secretaria.asp?cat=156\&sub=302\&sec $=10>$. Acesso em março de 2012.

BRAZ, V. Poluição dos Recursos Hídricos da Amazônia: Aspectos Urbanos. Em: 


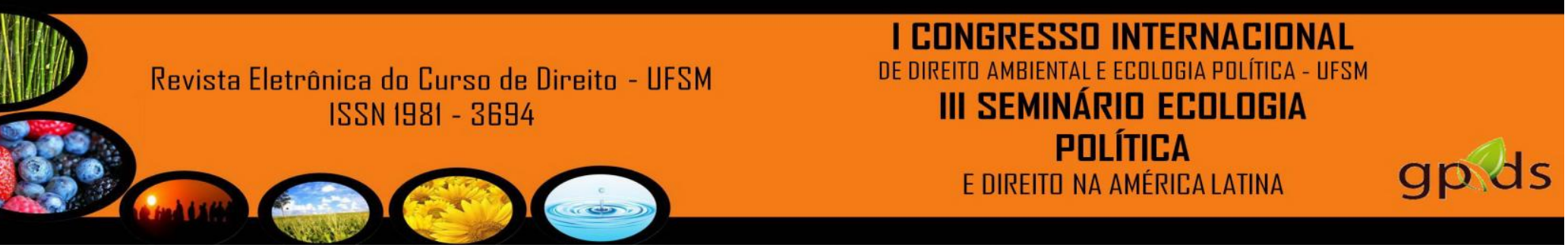

MACHADO, J.; SOUZA, R. Fatores determinantes de Construção de usinas hidrelétricas na Amazônia: bases para exigência de indenização. Em: ARAGÓN, L. (Org) Problemática do uso Local e Global da Água da Amazônia. NAEA. Belém. 2003.

MARENGO, J; NOBRE, A. SALATI, E; AMBRIZZI, T. Mudanças climáticas globais e seus efeitos sobre a biodiversidade - caracterização do clima atual e a definição das alterações climáticas do século XXI. Em Biodiversidade, $2^{\mathrm{a}}$ edição. Ministério de Meio Ambiente. Brasília. 2007.

MARGUILIS, S. Causes of Deforestation on the Brazilian Amazon. Paper No. 22. Disponível em http://wwwwds.worldbank.org/servlet/WDSContentServer/WDSP/IB/2004/02/02/000090341_2004 0202130625/Rendered/PDF/277150PAPER0wbwp0no1022.pdf.

MARTÍNEZ, J; RUANO, P. Aguas Subterráneas. Progensa. Sevilla. 1998.

MOENCH, M. Groundwater. The Challenge of Monitoring and Management. Em: GLEICK, P.H. The World's Water TheBienal Report Freshwater Resources. Island Press. Washintong. 2004.

MONTANA, M. Bacia Amazônica e Hidropolítica: Interdependência Hidrológica, Incipiente regime e Baixo Conflito. Tese Universidade de Brasília. Brasília. 2012.

MOOK, W.G.Isótopos Ambientales en el Ciclo Hidrológico: Principios y Aplicaciones. Programa Hidrológico Internacional Phi. Publicaciones del Instituto Geológico y Minero de España, Ministerio de Ciencia y Tecnología y Unesco. Madrid. 2002.

NEPSTAD, D; P.MOUTI-NHO e SOARES FILHO. A Amazonia em clima de mudança: reduzindo as emissoes de Carbono resultantes de desmatamento e degradação florestal em grande escala. IPAM, The Woods HoleResearch Center, UFMG. 2006.

NEPSTAD, D. Los círculos viciosos de la Amazonía: Sequía y fuego en el invernadero. Gland, Suiza: WWF Internacional, 2007.

NOBRE, C.; SAMPAIO, G.; SALAZAR, L. Mudanças Climáticas e Amazônia. Ver. Ciência e Cultura. Vol.59, N³. São Paulo. Jul/Set. 2007.

PROCÓPIO, A. Amazônia: ecologia e degradação social. São Paulo. Alfa-Ômega, 1992.

ROCHA, G. Usinas hidrelétricas, apropriação dos recursos Hídricos na Amazônia e o desenvolvimento regional. Em: ARAGÓN, L.E. Em: ARAGÓN, L. (Org) Problemática do uso Local e Global da Água da Amazônia. NAEA. Belém. 2003.

ROCHA H; NOBRE, C; BONATTI, J. WRIGHT, I; SELlERES, P. Vegetationatmosphere interation study for Amazonia deforestation using field data and a "single column" model.QuaterlyJournalofthe Royal MeteorologicalSociety. Vol. 122. No 531, 1996. 


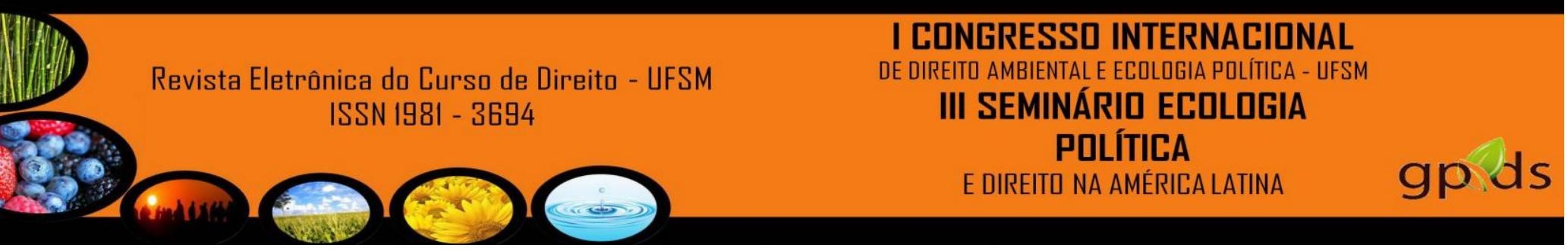

RUIVO, M. Uso da Água na Amazônia: Fontes de Poluição, Riscos, Consequências e Alternativas. Em: ARAGÓN, L. (Org) Problemática do uso Local e Global da Água da Amazônia. NAEA. Belém. 2003.

SOUZA J.; ROCHA, E.; COHEN, J. Avaliação dos Impactos Antropogênicos no ciclo da água na Amazônia. In Problemática do uso local e global da água da Amazônia. Aragon L. e Clüssener (org). Belém: NAEA, 2003. 